\title{
The Experience of Barometric Drifter Application for Investigating the World Ocean Arctic Region
}

\author{
S.V. Motyzhev, E.G. Lunev, A.P. Tolstosheev \\ Marine Hydrophysical Institute, Russian Academy of Sciences, Sevastopol, \\ Russian Federation \\ e-mail: marlin@marlin-yug.com
}

\begin{abstract}
Efficiency of the problem solution to create a regionally-oriented data computing system for marine dynamics and ecosystem evolution modeling and forecasting (that should be capable for providing reliable information for managerial decision making, justifying future economic projects and adjusting the existing ones) depends on development level of observational systems, environmental evolution, mathematical models and techniques for observational data assimilation. The analysis of the system as an observational segment of modern geo-informational technology allows us to draw a conclusion that the system of drifter observations is one of the most effective ones nowadays. Surface drifter network, continuously operating in the World Ocean, provides systematic operational data on the surface water circulation, thermal processes in the upper ocean and air pressure. Drifter data, acquired over the past 15 years, allowed one to improve and even change the existing concepts of patterns and mechanisms of regional climatic trend and hydrometeorological anomaly formation under effect of global processes in the Ocean-Atmosphere model (in the high latitudes as well). In the present paper the principle results of the analysis of expediency and feasibility of drifting systematic operative pressure field monitoring establishment in the near-surface atmosphere layer over the Arctic Ocean and the seas of the Russian Federation Arctic Zone have been considered.More than 30 drifters of BTC60/GPS/ice type, whose summarized lifetime as for June 2015 exceeded 6500 days, were deployed in the Arctic in 2012-2015. According to data acquired from the drifters, more than 155000 air pressure readings were received. The most intensive drifter observations were carried out in two regions: in the Beaufort Sea-Canada Basin and in the Central Arctic. The results of experiments revealed that hardware-software solutions implemented in polar modifications of barometric drifters provide reliable long-term operation of these apparatus as autonomous instruments of air pressure field operative systematic monitoring in the Arctic Region. With regard to relatively low cost and acceptable dimensions and weights barometric drifters may be considered as the elements of reliable and low-cost polar network of operative meteorological observations.
\end{abstract}

Keywords: air pressure, barometric drifter, Arctic area.

DOI: 10.22449/1573-160X-2016-4-47-56

(C) 2016, S.V. Motyzhev, E.G. Lunev, A.P. Tolstosheev

(C) 2016, Physical Oceanography

Introduction. Efficiency of solving the problems for creating a regionallyoriented data processing system for marine dynamics and ecosystem evolution modeling and forecasting (that should be capable of providing reliable information for managerial decision making, justifying future economic projects and adjusting the existing ones) depends on development level of observational systems, evolution of numerous modeling and techniques of observational data assimilation. The analysis of operational observational systems as a segment of contemporary geo-informational technology allows us to draw a conclusion that the system of drifter observations is one of the most effective ones nowadays. Surface drifter network, continuously operating in the World Ocean, provides systematic operational data on the surface water circulation, thermal processes in the upper ocean and air pressure. Drifter data, acquired over the past 15 years, allowed one to improve and even change the existing concepts of patterns and mechanisms of regional climatic trend and hydrometeorological anomaly formation under effect of global processes in the Ocean - Atmosphere model (in the high latitudes as well). In the present paper the principle results of the analysis of expediency and feasibility of drifting systematic operative pressure field monitoring establishment 
in the near-surface atmosphere layer over the Arctic Ocean and the seas of the Russian Federation Arctic Zone have been considered.

Air pressure in one of the most important meteorological elements upon which numerical weather modeling is carried out. The main characteristics of observational network should meet the requirements of several international programs of Intergovernmental Oceanographic Commission (IOC-UNESCO) of UNESCO and the World Meteorological Organization (WMO). Numerical models of weather forecast should meet the requirements of Global NWP program (highdefinition ones - HR NWP); climate variability observations - GCOS; development of marine observational system - GOOS. In these programs three levels of requirements for spatio-temporal resolution, timeliness (delay time) of data acquisition and delivery, as well as permissible error of measurements (Table) have been formulated: 1) minimum permissible (in the Table - "min.”); 2) optimal ("opt."), when reaching them, a significant improvement of system or model operation quality is obtained; 3) target ("targ.") or the most stringent requirements, when they are reached, further improvement is meaningless. The requirements of these programs for the baric field monitoring are summarized in [1].

WMO and IOC requirements for near-surface barometric observations

\begin{tabular}{|c|c|c|c|c|c|c|c|c|c|c|c|c|}
\hline \multirow{3}{*}{ Program } & \multicolumn{6}{|c|}{ Observation scale } & \multirow{2}{*}{\multicolumn{3}{|c|}{ Delay time, h }} & \multirow{2}{*}{\multicolumn{3}{|c|}{ Error, hPa }} \\
\hline & \multicolumn{3}{|c|}{ spatial, km } & \multicolumn{3}{|c|}{ temporal, $\mathrm{h}$} & & & & & & \\
\hline & $\min$. & opt. & targ. & $\min$. & opt. & targ. & $\min$. & opt. & targ. & min. & opt. & targ. \\
\hline$\overline{\text { Global NWP }}$ & 500 & 100 & 15 & 12 & 6 & 1 & 6 & 0.5 & 0.1 & 1 & 1 & 0.5 \\
\hline HR NWP & 20 & 5 & 1 & 6 & 1 & 0.5 & 2 & 0.5 & 0.25 & 1 & 0.65 & 0.5 \\
\hline GCOS & 500 & 300 & 200 & 24 & 6 & 3 & 12 & 6 & 3 & 1 & 0.65 & 0.5 \\
\hline GOOS & 100 & 63 & 50 & 48 & 30.2 & 24 & 7 & 4 & 3 & 15 & 11.4 & 10 \\
\hline
\end{tabular}

Large number of publications (their meaning from the point of view of observational system current status has been summarized in [2]) is dedicated to the analysis of problems that take place when monitoring of barometric meteorological parameter in the World Ocean Arctic Region with the required spatial-temporal resolution. Systemizing the available data on the Arctic study, the author of the abovementioned paper concludes that, although the studies in the Arctic with different aims are particularly relevant, their practical implementation remains technically and organizationally difficult and expensive. In the paper [3], which is devoted directly to the issue of atmospheric field monitoring in the Polar Regions, the fact that meteorological stations are sparsely distributed over the Arctic Ocean due to placement difficulties and high coast of maintaining is pointed out. Apparently, this circumstance complicates model forecast validation and may cause errors in the results.

Since 2010, there has been taking place a trend of changing the situation for the better. To a certain extent, this is due to the Marine Hydrophysical Institute (MHI) of Russian Academy of Sciences and "Marlin-Yug” Ltd. works on drifter technology development and introduction into the practice of polar and circumpolar studies [4]. The results of the analysis of these activities, in respect to the solution of the problem of systematic operative pressure field monitoring establishment in the Arctic, are considered below.

Barometric drifter. The construction of low-cost and technological polar observational network, that provides near-surface air pressure control with required spatio-temporal resolution, is possible through the comprehensive solution of two problems. The first one is the construction of low-cost measuring instrument with at least two years autonomy. It should also be resistant to influencing factors 48

PHYSICAL OCEANOGRAPHY NO. 4 (2016) 
characteristic of polar operating conditions. The second one is adaptation of measuring instrument interface to the existing systems for operative delivery of data to users.

Solution of these problems may be based on the developments accomplished in MHI in 2000 - 2015. It is essential that the results of these developments have been tried out in long-term in situ experiments in different regions of the World Ocean. It seems appropriate to use SVP-B type autonomous barometric drifter [5], adapted to the operational conditions of the polar regions, as a basic element of polar observational network. The drifter includes air pressure measuring channel with barometric port, which provides correct interaction between the sensor and the atmosphere under influence of wind and wave effect, and sea surface temperature (SST) measuring channel. Drifter locations are measured by the integrated Global Positioning System GPS receiver. Measurement data are transmitted to users via Argos or Iridium satellite communication systems.

Air pressure field control channel includes the aggregate of all technical, informational and software tools which participate in air pressure measurement, quality control and delivery of data to users. The structure of this channel is represented in Fig. 1. MS5534B type sensor (Intersema, Switzerland) is used as a primary pressure transducer. As is shown in [6], when sensors are calibrated individually, the error of pressure measuring within $850-1055 \mathrm{hPa}$ range at environment temperature from -20 to $+20{ }^{\circ} \mathrm{C}$ does not exceed $2 \mathrm{hPa}$ during 12 month.

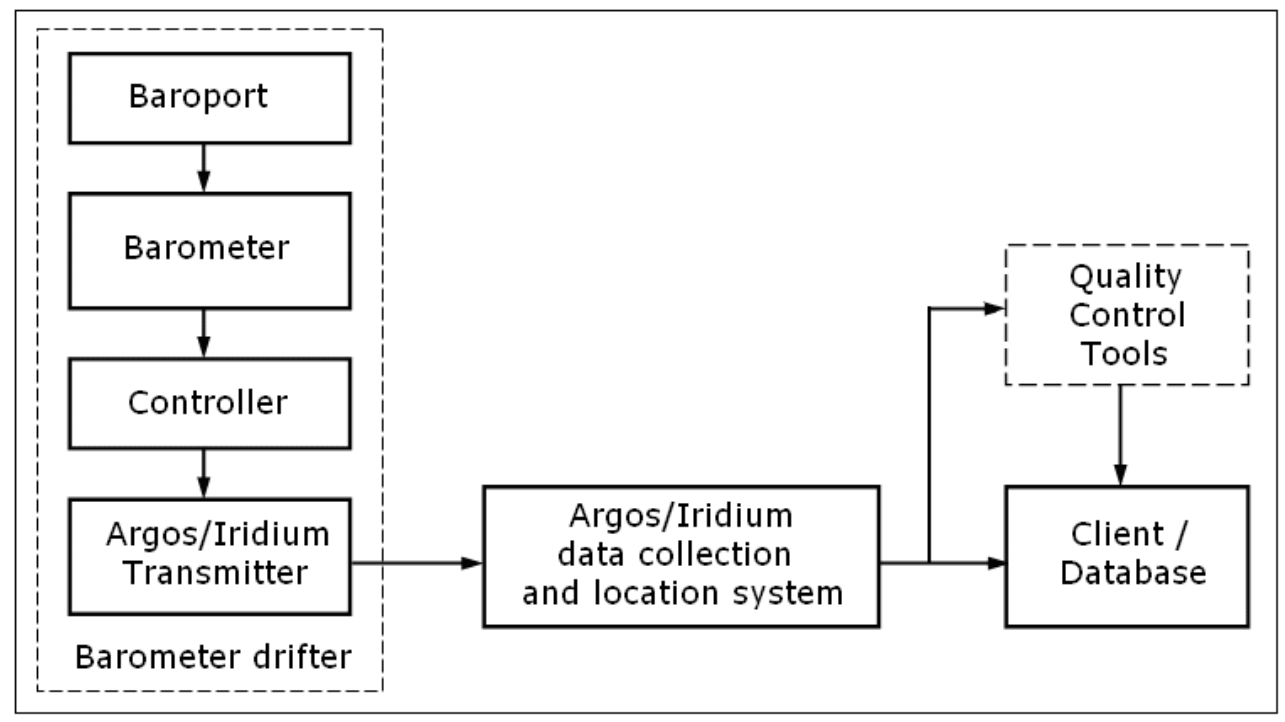

Fig. 1. The structure of arrangement of air pressure drifter monitoring channel

The most important indicator of barometric drifter effectiveness, as an autonomous unattended observational instrument, is reliability of its meteorological and operational characteristics. Long-term tests of specialized modification of MHI barometric drifter had been carried out at cape Barrows, at the North of Alaska. These tests are one of the experiments on the basis of which it is possible to draw a conclusion on the possibility and feasibility of air pressure monitoring network construction in the Arctic Region utilizing the above mentioned barometric drifter. Comparative tests have been carried out upon the 
initiative of University of Washington staff in order to assess operational characteristics of barometric drifters (from different manufacturers) in polar conditions. Barometric drifter ID128647, developed by MHI and manufactured by "Marlin-Yug” Ltd, has been installed at the cape Barrow test ground in early July 2013 together with barometric drifters from other manufacturers (including MetOcean (Canada) and Pacific Gyre (USA)). Duration of barometric drifter autonomous operation made up 857 days. During that time more than 20000 hourly readings of air pressure, environmental temperature and coordinates, according to built-in GPS receiver data, were performed and transmitted via Argos-2 satellite channel. On 13 November 2015, barometric drifter stopped data transmission due to low battery. For objective reasons we do not have continuous data series. Nevertheless, available fragments allow us to draw valid conclusions on the quality of measurement results.

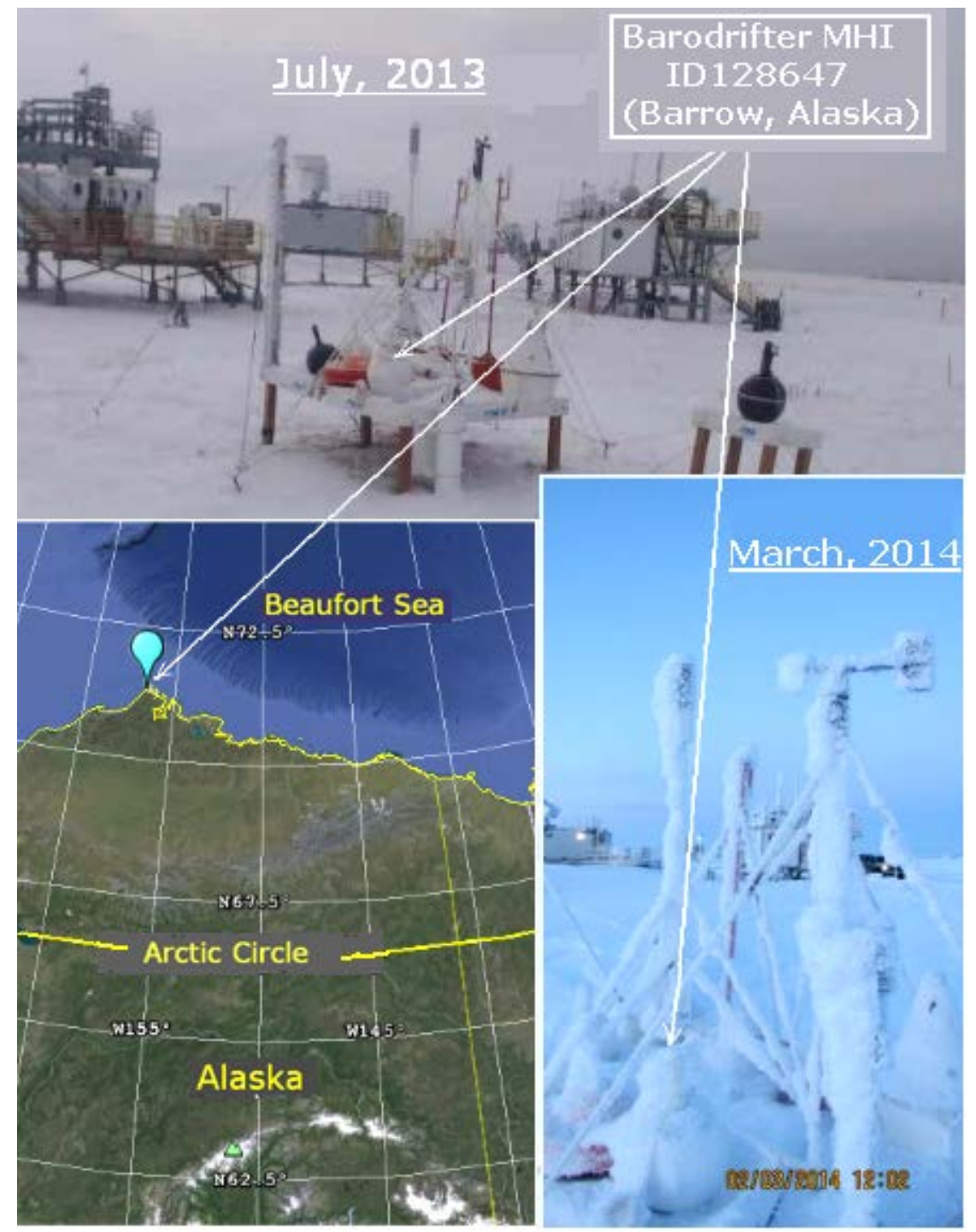

Fig. 2. Barometric drifter tests in the North of Alaska 


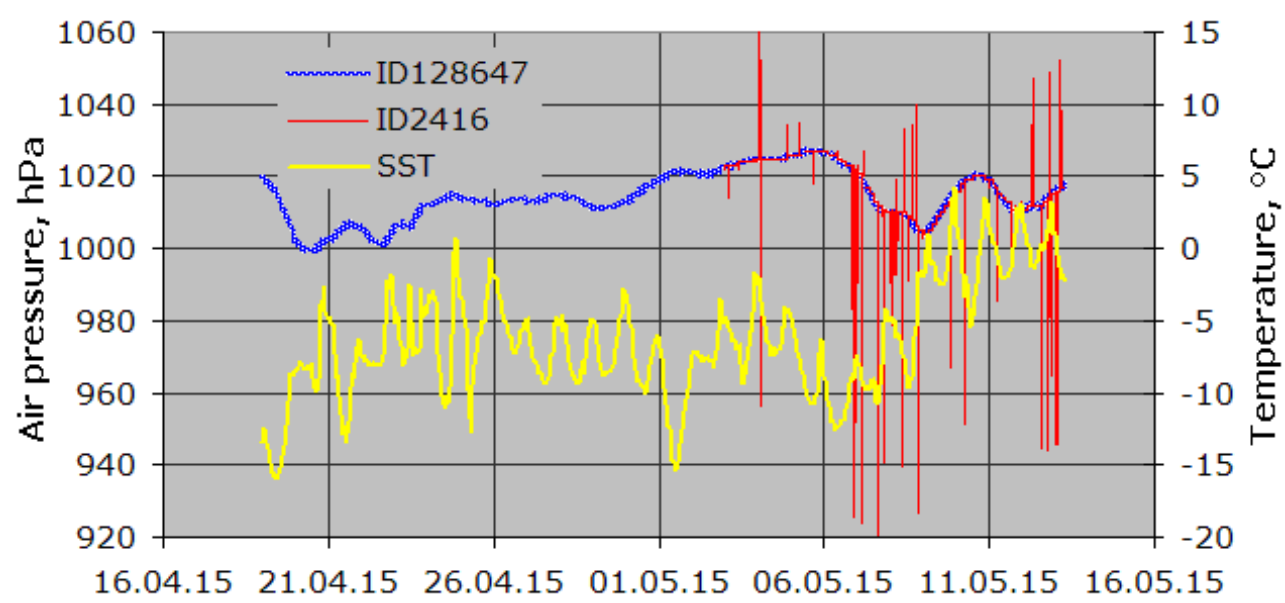

Fig. 3. Fragments of air pressure time series according to data of ID128647 and ID2416 barometric drifters, and sea surface temperature (SST) - according to ID128647 barometric drifter data (the results of tests performed at test ground in Alaska)

Test conditions can be seen in Fig. 2, the quality of measurement results can be seen from the graphs in Fig. 3. Air pressure graphs have been plotted according to the data acquired from barometric drifters ID128647 (MHI) and ID2416 (unknown manufacturer). Environment temperature graph has been plotted according to the data of ID128647 barometric drifter. As is obvious from Fig. 3, air pressure measurement channel of ID128647 barometric drifter remained operational throughout the entire period of observations, whereas there were numerous failures in barometric drifter ID128647 data.

The results of correlation of air pressure and drift trajectory time series according to GPS receiver data of ID52494 MHI barometric drifter and Canadian profiling system Polar Ocean Profiling System (POPS) (in April 2010 they were deployed $77 \mathrm{~km}$ from the North Pole and a few meters from each other) are indicative in assessing the operational characteristics. Trajectories and graphs (reconstructed according to data of barometric drifter and POPS system) of air pressure time series are represented in Fig. 4. For almost three months barometric drifter locations were determined without omissions and failures by installed GPS receiver and were transmitted with 1 hour interval. This allowed us reliably assess drift parameters, unlike the fragmentary trajectory measurements carried out by POPS system.

Similar conclusions can be drawn about the results of air pressure observations whose time series are graphically shown in Fig. 4. Judging by the graphs, there are up to $7 \mathrm{hPa}$ (June 2010) differences between the POPS system data and MHI barometric drifter data. In the same figure the graph (shown in green) of difference of barometric drifter measurement results from the air pressure model assessments according to the data of Meteo-France (France) meteorological center quality control system is represented. It is obvious from the graph that the failures in POPS system measurements are the cause of the differences. 


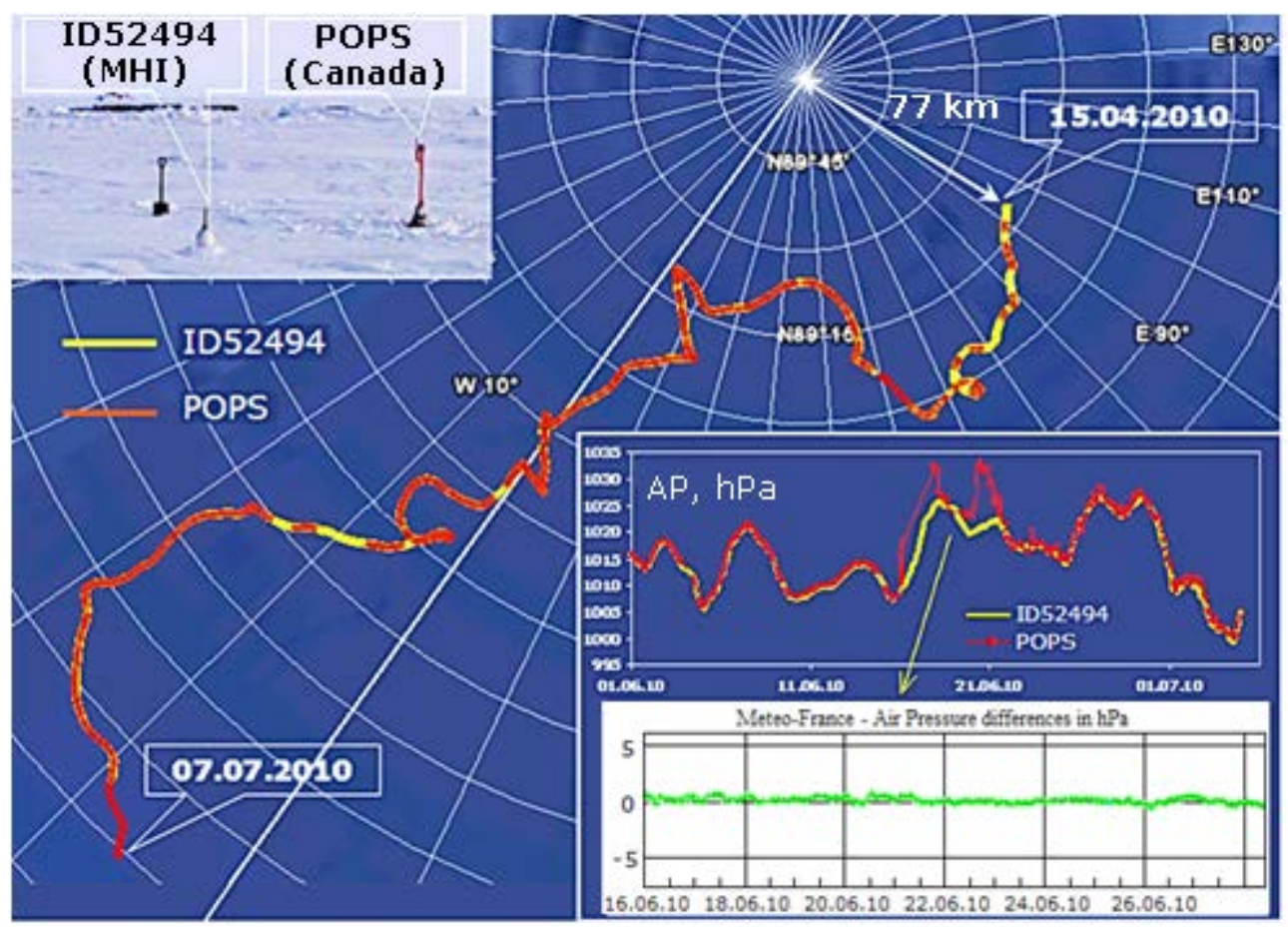

Fig. 4. Ice floe drift and results of air pressure (AP) observations according to the data of ID52494 barometric drifter (MHI) and POPS profiling system (Canada)

Technical and methodological solutions that had been implemented in the considered polar drift experiments and had been continuously tested in Arctic conditions became the basis for construction of specialized autonomous instruments for investigation of Arctic and methods of their application. Such instruments include BTC60/GPS/ice type temperature-profiling drifters developed in MHI. The experience of their implementation has been described in [4].

Some results of in situ experiments. More than 30 drifters of BTC60/GPS/ice type whose summarized lifetime as for June 2015 exceeded 6500 days were deployed in the Arctic in 2012 - 2015. According to data acquired from the drifters, more than 155000 air pressure readings were received. The most intensive drifter observations were carried out in two regions: in the Beaufort Sea - Canada Basin and in the Central Arctic. The trajectories of some drifts in the Central Arctic are represented in Fig. 5. Three drifters performed synchronous air pressure measurements with $1 \mathrm{hr}$ interval for 396 days (September 2013 - October 2014). Three-month snippets of data, according to which one can assess real spatialtemporal air pressure field variability, are shown at the graphs represented in Fig. 5.

The creation of systematic operative observations of air pressure field in the Arctic Region as a segment of informational-measuring modeling system will enhance the forecast quality. Fig. 6 taken from the paper [3] can be a clear illustration of this fact. As it can be seen from graphs on which the results of air 
pressure field modeling are represented, assimilation of drifter data provides significant refinement of model assessments. As a consequence, this also reduces the probability of erroneous forecasts.
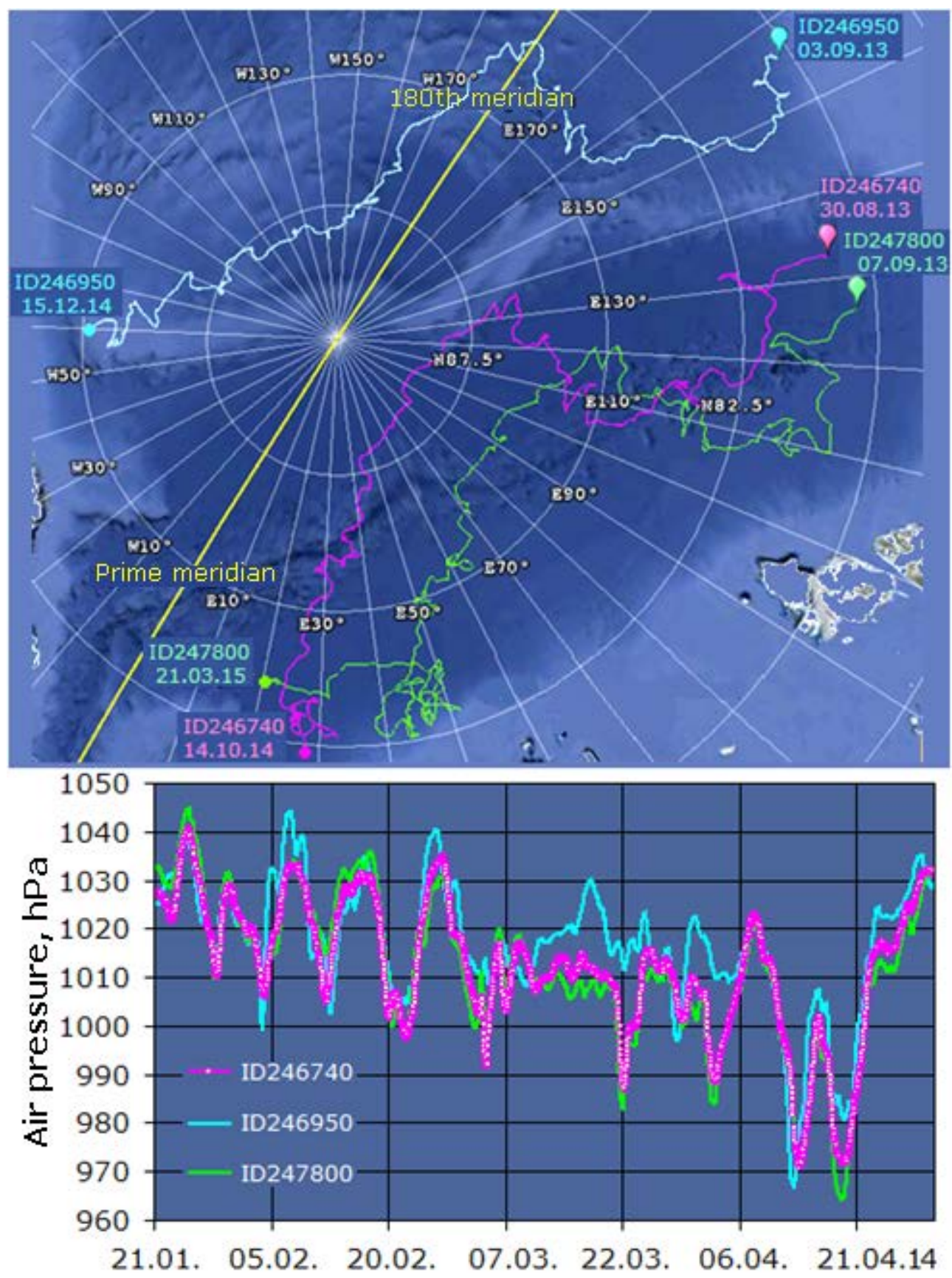

Fig. 5. Trajectories and air pressure time series according to the data of BTC60/GPS/ice ID247800, ID246740 and ID246950 barometric drifters in January - May 2014 
Since barometric drifters are autonomous measuring instruments, this eliminates the possibility of drifter measurement verification by direct control of measuring channels in the floats. The reliability of parameters (which are measured in situ by drifters) can be assessed by the system of remote quality control of marine contact observations Quality Control Tools [7]. Verification method based on comparison of global air pressure field model calculation results with the drifter measurement data is implemented in this system (which is supported by MeteoFrance meteorological center). Pressure field models are developed and supported by independent national and international hydrometeorological centers. The results of drifter and model data comparison are available on the website [8]. These data can be assessed using the $W M O$ numbers (unique for each drifter) under which drifter data are disseminated in the Global Telecommunication System. For the past 15 days the data are represented graphically. For the past 6 months the information is represented by the data on the operating quality of drifter measuring channel.

\section{Sea Level Pressure (SLP) Reanalyses}

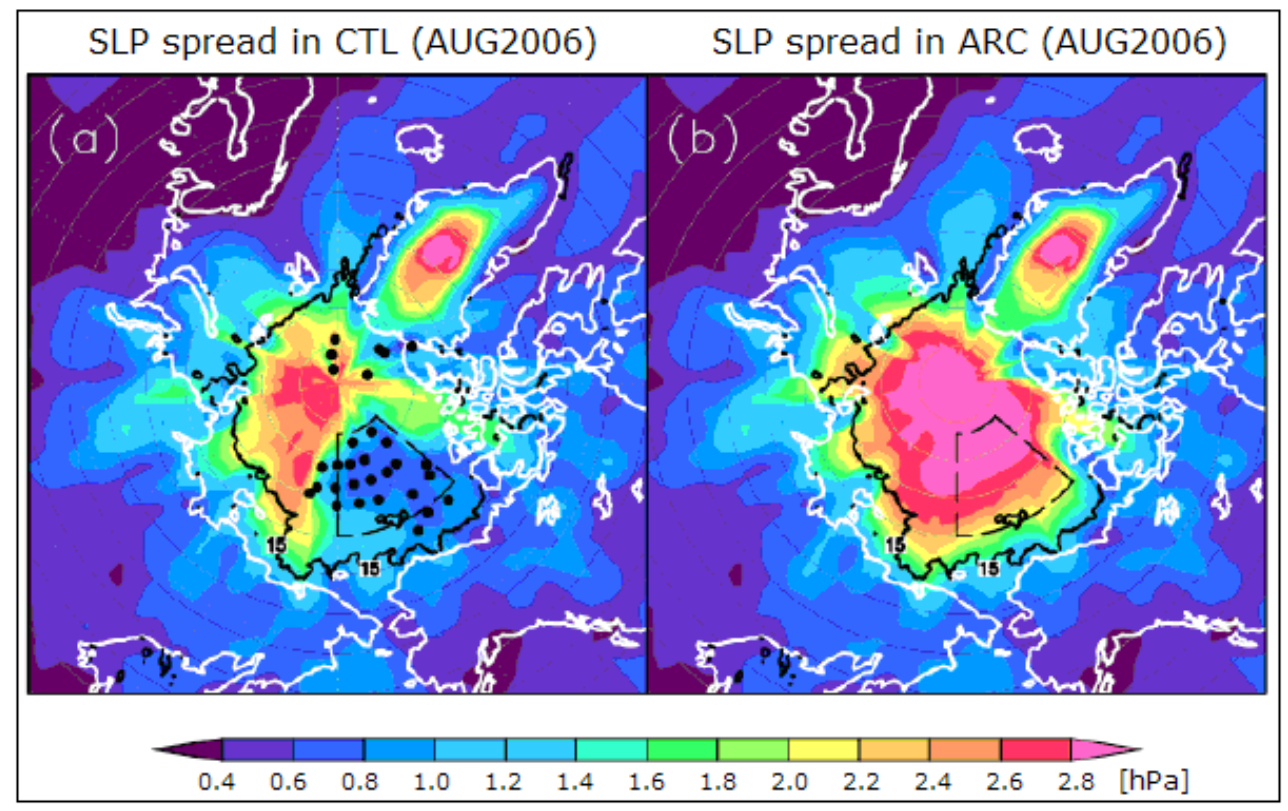

Fig. 6. Model assessments of air pressure field with regard (on the left) and with no regard (on the right) for the drifter data [3]. The positions of barometric drifters whose data were assimilated in the model are marked by black dots

In Fig. 7 the results of air pressure measurement quality assessment are shown. The measurements were carried out by BTC60/GPS/ice ID245950/WMO4800541 thermoprofiling barometric drifter that had been deployed on 30 August 2013 in the point with $76.43{ }^{\circ} \mathrm{N}$ and $178.87{ }^{\circ} \mathrm{E}$ coordinates. The drifter remained fully operational and drift duration (its trajectory is shown in Fig. 7, a) made up 846 days as at 23 December 2015. During that period the drifter performed more than 20300 air pressure measurements with $1 \mathrm{hr}$ interval. The graphs of air pressure value (measured by the barometric drifter in December 2015) differences from the 
ones calculated according to the models via Meteo-France Quality Control Tool (France) are shown in Fig. 7, $b$. Monthly average statistical values of measurement quality (the measurements were carried out in June - November 2015) in comparison with the model ones are represented in Fig. 7, $c$. The assessments of root-mean-square deviation (RMSD) of air pressure measurement results do not exceed, and in most cases are even lower than RMSD mean value calculated by the data from all barometric drifters of the global observational network.
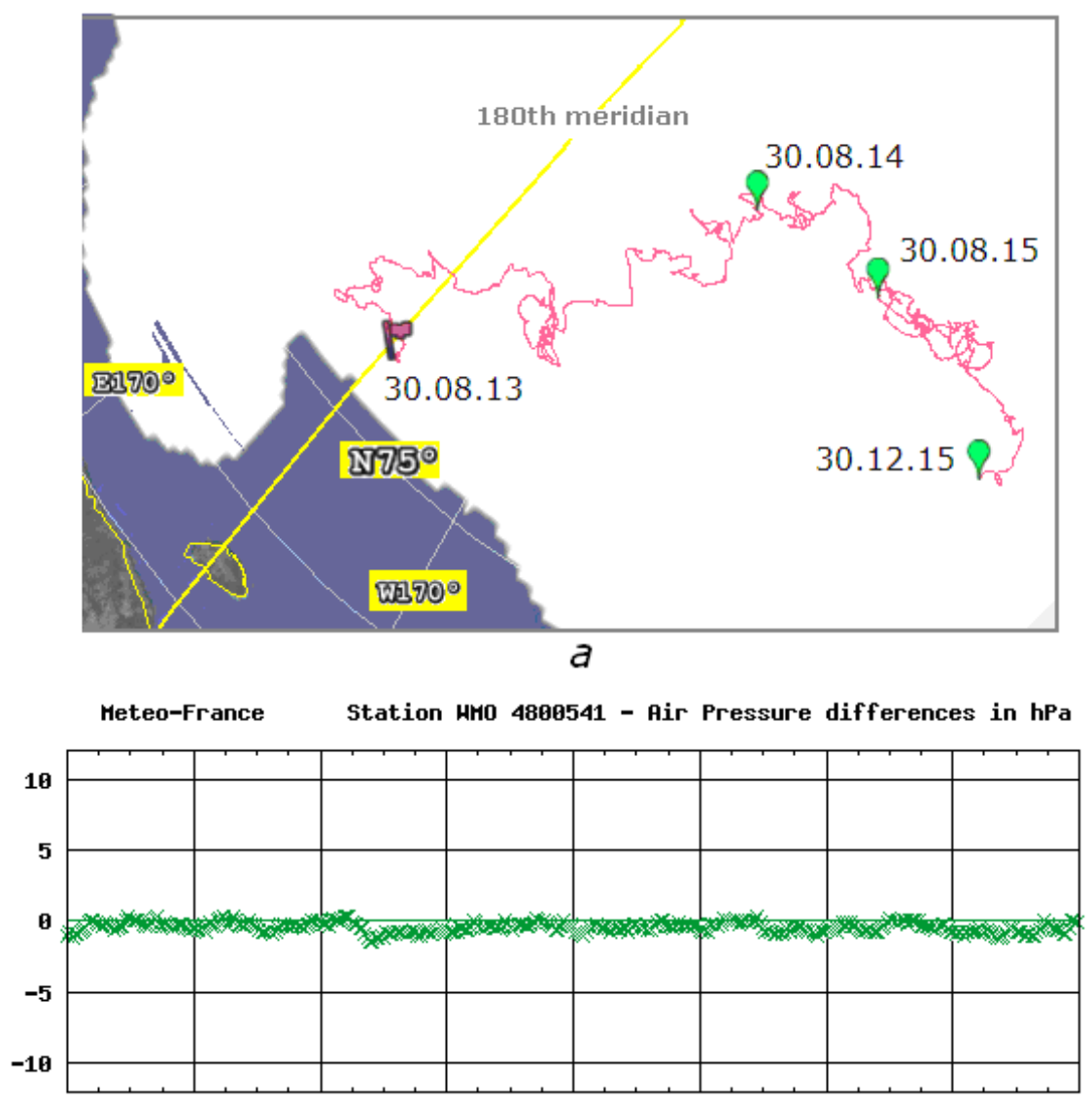

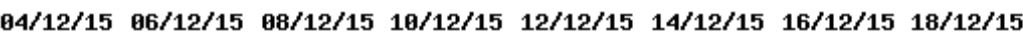

$b$

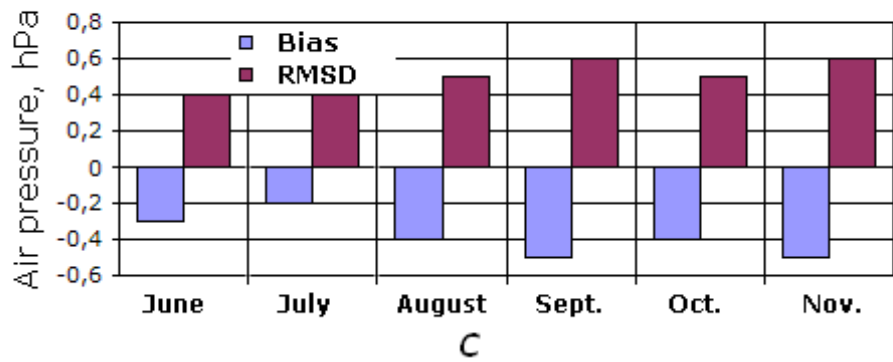

Fig. 7. Drift trajectory $(a)$, graphs of measured air pressure value differences from the ones calculated by the model $(b)$ and monthly average statistical values of measurement quality $(c)$ according to data of BTC60/GPS/ice ID245950/WMO4800541 barometric drifter

PHYSICAL OCEANOGRAPHY NO. 4 (2016) 
Conclusions. The results of experiments revealed that hardware-software solutions implemented in polar modifications of barometric drifters provide reliable long-term operation of these apparatus as autonomous instruments of air pressure field operative systematic monitoring in the Arctic Region. With regard for relatively low cost and acceptable dimensions and weights barometric drifters may be considered as the elements of reliable and low-cost polar network of operative meteorological observations.

The results of polar experiments had been presented at roundtable discussions, forums and salons arranged in 2015 by different ministries and departments of the Russian Federation, and were recommended for implementation.

\section{REFERENCES}

1. Lunev, E.G., 2012, "Sovershenstvovanie kanalov kontrolya polya atmosfernogo davleniya dlya poverkhnostnykh dreyfuyushchikh buev [Improvement of air pressure field control channels for the surface drifting buoys]”, PhD thesis, Sevastopol, MGI NAN Ukrainy, 180 p. (in Russian).

2. Pisarev, S.V., 2012, "Opyt primeneniya avtomaticheskikh dreyfuyushchikh ustroystv dlya issledovaniya vodnoy tolshchi i ledovogo pokrova Arktiki v nachale XXI v. [The experience of automatic drifting apparatus application for the Arctic water column and ice cover investigation in early $21^{\text {st }}$ century]”, Arktika: ekologiya i ekonomika, no. 4, pp. 66-74 (in Russian).

3. Inoue, J., Enomoto, T. \& Miyoshi, T. [et al.], 2009, "Impact of observations from Arctic drifting buoys on the reanalysis of surface fields”, Geophys. Res. Lett., vol. 36, L08501, doi:10.1029/2009GL037380.

4. Motyzhev, S.V., Lunev, E.G. \& Tolstosheev, A.P. [et al.], 2016, “Opyt primeneniya termoprofiliruyushchikh drifterov dlya issledovaniy arkticheskogo regiona Mirovogo okeana [The experience of thermoprofiling drifter application for the World Ocean Arctic Region investigations]”, Arktika: ekologiya i ekonomika, no. 1, pp. 38-45 (in Russian).

5. Sybrandy, A.L., 2009, "Global drifter program. Barometer drifter design reference”, DBCP Report., no. 4, http://www.jcommops.org/dbcp/community/standards.html (access date 09.02.2015).

6. Tolstosheev, A.P., 2009, “Issledovanie metrologicheskikh kharakteristik izmeritel'nykh kanalov atmosfernogo davleniya avtonomnykh dreyfuyushchikh buev [The investigation of meteorological characteristics of autonomous drifting buoy air pressure channel]", Ekologicheskaya bezopasnost' pribrezhnoy i shel'fovoy zon $i$ kompleksnoe ispol'zovanie resursov shel'fa, iss. 17, pp. 113-121 (in Russian).

7. http://www.jcommops.org/dbcp/data/qc.html (access date 25.05.2016).

8. http://www.meteo.shom.fr/qctools (access date 25.05.2016). 